\title{
Evaluation of Fracture Toughness for Ceramic Materials
}

\author{
Toshimitsu FUJII') and Tetsuro NOSE')
}

1) Material Research Laboratory-I, Nippon Steel Corporation. Now at Engineering Ceramic Division-III, Japan Fine Ceramics Center Mutsuno, Atsuta-ku, Nagoya, Aichi-ken, 465 Japan. Kawasaki, Kanagawa-ken, 211 Japan.

2)Material Research Laboratory-I, Nippon Steel Corporation, Ida, Nakahara-ku,

(Received on December 15, 1988; accepted in the final form on May 19, 1989)

\begin{abstract}
Toughening mechanisms hitherto proposed, such as microcracking, crack-path-deflection, crack-bowing, and transformation-induced-plasticity, are briefly introduced. The increase in crack resistance (rising $R$-curve) due to the process zone wake is discussed in relation to test methods and precracking techniques. Stable crack extension is apt to be accompanied by the increase in crack resistance due to the wake of transformation or frictional interlocking, whereas pop-in crack extension seems to be little atterided by these phenomena. The loading rate dependence of $K_{1 C}$ value is also discussed. The $K_{\mathrm{IC}}$ value can be affected by the time dependent phenomena such as stress corrosion cracking even at room temperature and crack tip blunting, stable crack extension, etc., at elevated temperatures.

Various test methods tentatively used to evaluate the critical stress intensity factor, $K_{\mathrm{IC}}$ for ceramic materials are explained, and their advantages and disadvantages are discussed, partly referring to the results of the round robin tests organized by the Japan Fine Ceramics Association (J.F.C.A.). The bridge-indentation method, a new precracking technique, is also briefly explained.
\end{abstract}

KEY WORDS: ceramics; fracture toughness; test method; precrack; toughening mechanisms; $R$-curve; loading rate dependence.

\section{Introduction}

Brittle fracture is inherent to ceramic materials, although remarkable improvements have been recently achieved in strength and toughness. Therefore, plane strain fracture toughness, $K_{\text {IC }}$, is considered to be a much more important property in ceramic materials than it is the case in steels. Compared to steels, ceramics might seem to be ideal materials whose fracture is best expressed in terms of linear elastic fracture mechanics (LEFM), because no sign of macroscopic plastic deformation precedes the fracture in most ceramic materials. On the other hand, however, some specific problems have arisen due to the low $K_{\text {IC }}$ values of ceramics, such as occurrence of fracture from micrometric defects not much larger than the grain size, ${ }^{1)}$ fracture resistance increase with crack extension, and so on.

Nevertheless, the $K_{I C}$ value is one of the most important and useful parameters to be referred to for improving the strength of ceramics and/or for choosing suitable materials for specific uses. No standard test method, however, is yet established to evaluate the $K_{\text {IC }}$ of ceramics, although a variety of test methods has been proposed and some of these are widely utilized to tentatively evaluate the " $K_{\text {IO }}$ " of ceramics. The Japan Fine Ceramic Association (J.F.C.A.) has been organizing a research committee for the feasibility of standardization of test methods. A subcommittee for fracture toughness had studied six methods, and had carried out round robin tests for four years. ${ }^{2-5)}$ Two test methods, the single-edge-pre- cracked-beam method and the indentation-fracture method, had passed the examination, ${ }^{5)}$ and were included in the original form of a Japanese Industrial Standard (JIS) in March, 1989. The standard will be published within a year. (See Secs. 3.4 and 3.6 for details.) European countries and the United States are also eager to standardize the test methods for mechanical properties of ceramics, and an international program on round robin tests is now in progress for the fracture toughness of ceramics.

The present paper covers the state of the art of the test methods for evaluating $K_{\text {IC }}$ and some problems which are inherent to these methods.

\section{Precaution in Evaluating and Referring to $K_{\text {IC }}$}

\subsection{Toughening Mechanisms}

Brittle fracture of ceramic materials has been considered to be well expressed by the plane strain fracture toughness, $K_{\text {IC }}$, in a similar way to the fracture of metals. Unlike metals, however, most ceramic materials are considered to fracture without any plastic deformation, and instead some substitutive mechanisms for stress shielding around the crack tip have been proposed to explain the moderate $K_{\mathrm{IC}}$ values of polycrystalline ceramics. Those are as follows.

\subsubsection{Microcracking}

The anisotropy of elastic constants and thermal expansion in ceramic crystals give rise to local stresses in the microstructure, and can cause microcracks at 

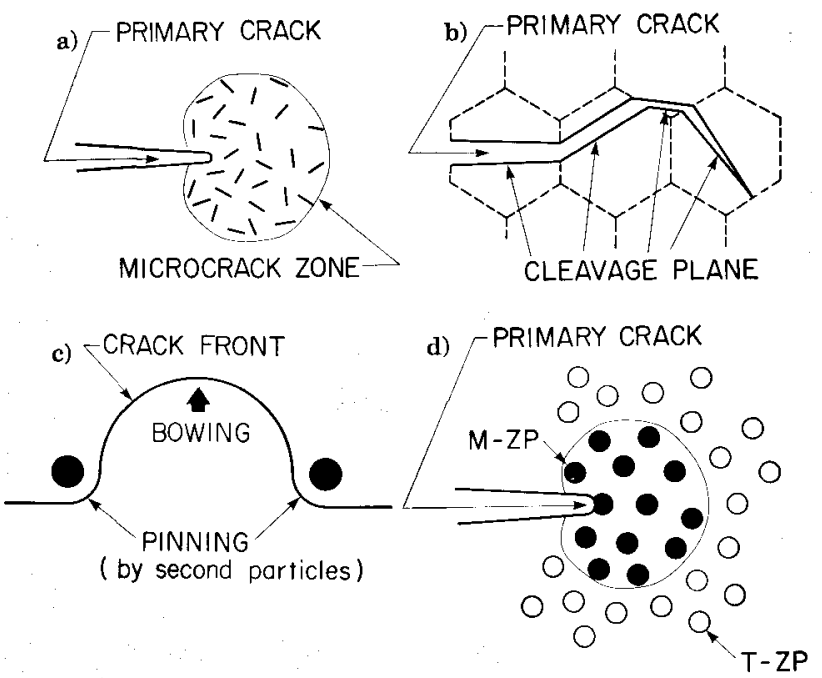

M-ZP: Monoclinic zirconia particle

T-ZP: Tetragonal zirconia particle

(a) Microcracking

(b) Crack-path-deflection

(c) Crack-bowing

(d) Transformation-induced-plasticity

Fig. 1. Toughening mechanisms in ceramics.

grain boundaries. ${ }^{6,7)}$ As shown in Fig. 1(a), a group of microcracks surrounding the primary crack tip has bcen thought to play the role of a process zone which might shield the stress concentration at the tip, ${ }^{8,9)}$ although no such microcrack zone has yet been observed. It was shown by Kachanov and Montagut's analyse ${ }^{10)}$ on the interaction of a primary crack with microcrack arrays, that the effective stress intensity factor, $K_{\mathrm{I}}$, around the primary crack tip is reduced to two thirds of the "non-shielding" $K_{\mathrm{I}}$ at least in special cases where parallel microcracking is found just above (and/or below) the primary crack tip, as shown in Fig. 2(a). However, it was also shown that the other arrangements of microcracks do not reduce the effective $\kappa_{\mathrm{I}}$, or increase it, as shown in Figs. 2(a) and 2(b). (The upper portions in Fig. 2 show the situation and the orientation of microcracks, and the lower figures show the variation of $K_{\mathrm{I}}$ with these parameters, where $K_{1}^{0}$ denotes the $K_{1}$ in the absence of microcracks. The $K_{\mathrm{I}}$ is reduced inside the circle in the left (shaded regions), but is increased outside both circles.) The balance of these effects seems to be uncertain: i.e., whether the effective $K_{\mathrm{I}}$ is reduced, or increased by the presence of microcracks along the crack front as a whole. The effect of microcracks might be inseparable from the following mechanism.

\subsubsection{Crack-path-deflection}

Remarkable deflection of the crack path is often observed in examination of specimen surfaces, and has been suspected to be a cause for the high $K_{\mathrm{IC}}$ values of polycrystalline ceramics compared with those of single crystals. The decrease of the effective $K_{\mathrm{I}}$ around the crack tip due to the deflection, or the increase of $K_{\mathrm{JC}}$ in other words, has been estimated to be at most $40 \%,{ }^{111}$ in the case of simple geometry shown
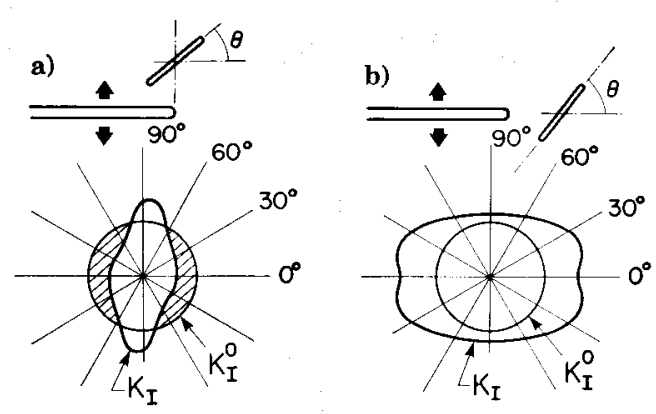

(a) A microcrack above the primary crack

(b) A microcrack in front of the primary crack

Fig. 2. Variation of the stress intensity factor, $K_{I}$, at the primary crack tip with the microcrack orientation. (after Kachanov and Montagut ${ }^{10}$ )

in Fig. 1(b). Successive link of microcracks is considered to be another cause for the deflection, and pronounced deflection has been known to occur in composite ceramics reinforced with whiskers of high aspect ratio. ${ }^{12)}$ Crack-branching is a striking aspect of the deflection. ${ }^{13)}$ Incidentally, the crack-path-deflection is often accompanied by a rising $R$-curve which will be described in Sec. 2.2.

\subsubsection{Crack-bowing}

Microstructure of ceramics is reflected in the shape of the crack front in micrometric scale. Especially, the crack front is apt to be pinned down by second particles and/or pores, and hence is apt to bow out partially, ${ }^{14)}$ as shown in Fig. 1(c). The "bowing", or the "pinning" in other words, of the crack front is thought to toughen the ceramics.

\subsubsection{Transformation-induced-plasticity (TRIP)}

It is well known that the tetragonal phase in zirconia is stabilized by the addition of calcia, ceria, magnesia, yttria, and so on. The tetragonal phase is metastable and easily transforms to the monoclinic phase in the stress field around the crack tip, which can be thereby blunted, as shown in Fig. 1(d). Dilatation accompanies the transformation and decreases the tensile stress around the crack tip, even if the amount of the transformation is insufficient to blunt the crack tip. The same or analogous phenomena can occur in composites of zirconia particles embedded in an alumina matrix, ${ }^{15)}$ or in other composite systems. ${ }^{16)}$ The increase in $K_{10}$ due to TRIP depends upon the Young's modulus, the volume fraction of transforming grains, the width of transformation zone, and the transformation strain. ${ }^{17) * 1}$ These phenomena have been well documented in a number of papers. ${ }^{18,19)}$

\subsection{Dependence of Fracture Resistance on Crack Length and Loading Rate}

Because of the low $K_{\mathrm{IC}}$ values of ceramic materials, there arise some hindrances which disturb the adequate evaluation of $K_{\mathrm{IC}}$. The extent of the disturbance is considered to differ not only with materials but also by test methods. 


\subsection{1. $R$-curve Behavior}

In some cases, it has been observed that the resistance to crack extension is an increasing function of the crack extension length, which is termed a "rising $R$-curve". The before-mentioned TRIP can form a kind of process zone around the primary crack tip, inside of which a compressive stress field develops due to dilatation accompanying the transformation, as shown in Fig. 3(a). The compressive stress can not be fully released by the crack extension across the zone, and residual compressive stress is imposed upon the frontal process zone newly-formed around the crack tip. Thus, the compressive residual stress will increase with the increase of the " process zone wake" length, which has been considered to result in the rising $R$-curve in zirconia shown in Fig. $3(\mathrm{~b}) .^{19-21)}$ It has been reported that the $R$-curve is flattened for the crack extension in zirconia under displacementcontrolled loading, as shown in Fig. $4,{ }^{22)}$ which might manifest the plateau in Fig. 3(b).

Another type of the process zone wake has been considered to arise from a kind of crack-path-deflection as described before. A to-and-fro track of the primary crack extension is frequently observed in the
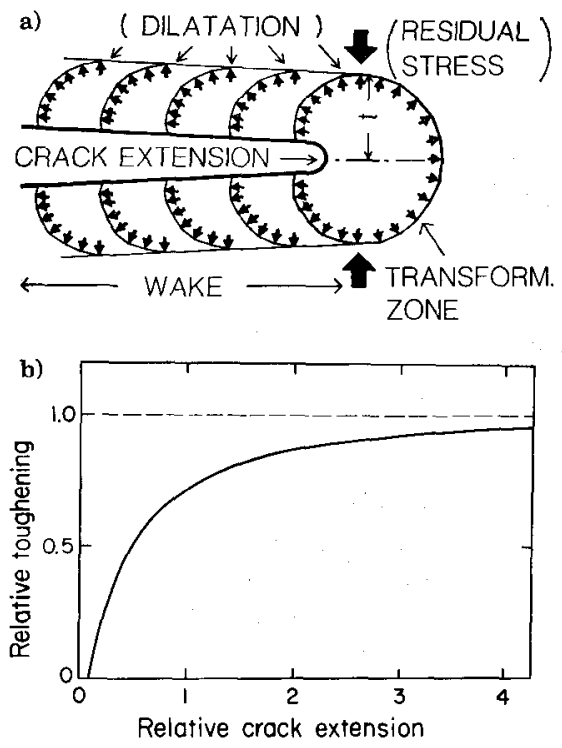

Fig. 3. (a) Compressive residual stress due to the transformation zone wake, and (b) relative toughening (normalized by the saturation value) with relative crack extension (normalized by the wake thickness, t). (after Marshall et al.20)

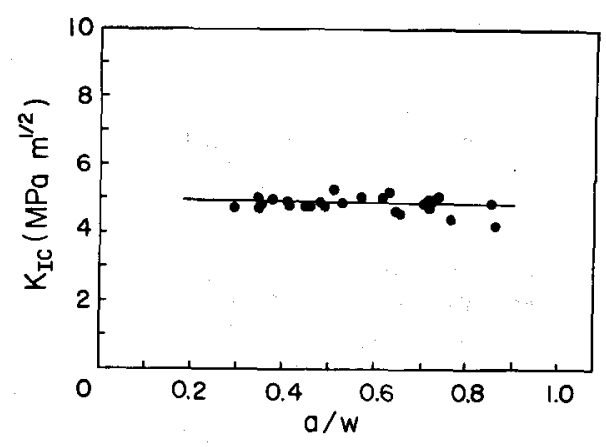

Fig. 4. R-curve for partially stabilized zirconia: the slope is 0.13 . (after Wieninger et al. ${ }^{22)}$ ) surface of a specimen, which might result from successive link of microcracks formed in the grain boundaries ahead of the primary crack tip. As shown in Figs. 5(a) and 5(b), if the two facing surfaces of the crack are locally in contact with each other, or if the link is locally incomplete, the "frictional interlocking of grains" or "ligament bridging "11) would decrease the effective stress around the primary crack tip, which has been considered to result in the rising $R$-curve of coarse-grained alumina shown in Fig. 6. ${ }^{13,22-24)}$ The frictional interlocking of grains is more pronounced in the stable crack extension of whisker reinforced ceramics, and is called "pull-out". ${ }^{25)}$

The $R$-curve behavior is not necessarily inherent to the material tested, but can differ with the precracking procedure and/or the test method used. As shown in Fig. 7, the $K_{\mathrm{I}}$, value for sintered silicon carbide (SC-850) is independent of the precracking procedures and the crack extension length, but this is not the case for a coarse-grained alumina (ADS-11) having the average grain size of $15 \mu \mathrm{m} .{ }^{26,27)}$ (See Sec. 3.4 for the precracking technique.) The $K_{\mathrm{IC}}$ value for the alumina is also independent of the pop-in crack length, but " $K_{\mathrm{IC}}$ " increases with stable crack extension. The pop-in crack surface is characterized by transgranular fracture appearance, whereas intergranular fracture appearance is dominant in stable crack extension, indicating that the rising $R$-curve is caused by "frictional interlocking of grains" or "ligament bridging". The rising $R$-curve in coarse grained alumina has been well documented in past litera-
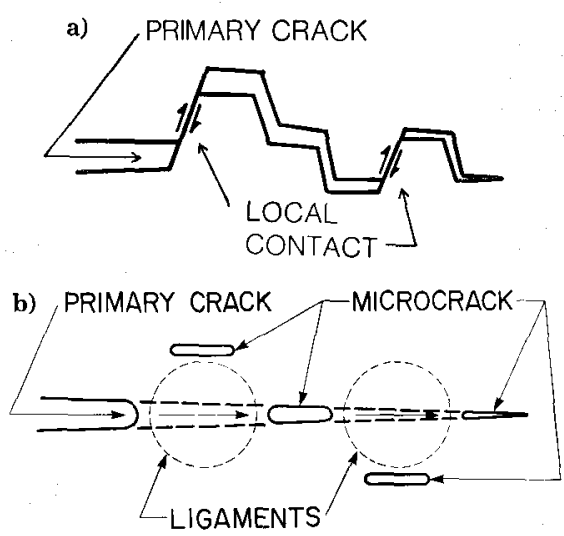

Fig. 5. (a) Frictional interlocking of grains, and (b) ligament bridging. (after Freiman ${ }^{11}$ )

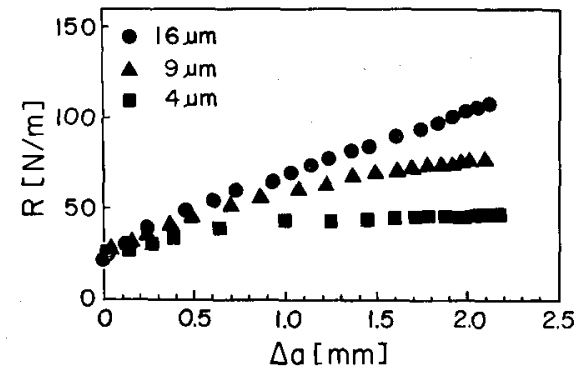

Fig. 6. Crack resistance curves for alumina with different grain size: the crack resistance data, $R$, were evaluated by a compliance method using SENB specimens described in Sec. 3.2. (after Deuerler t $_{\text {al. }}{ }^{24}$ ) 


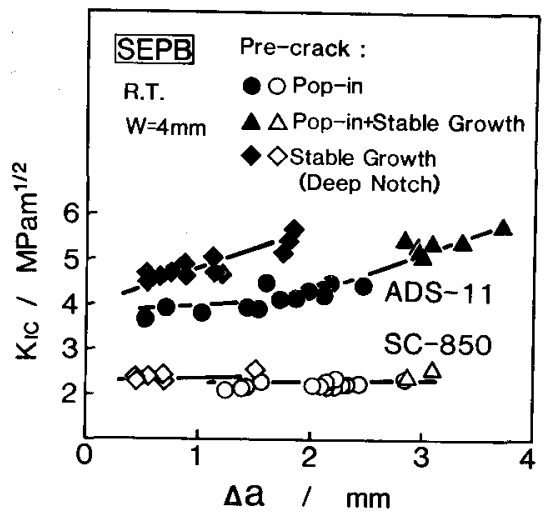

Fig. 7. Dependence of the $K_{\text {IC }}$ value on the crack extension length for silicon carbide (SC-850) and alumina (ADS-11): the $K_{\text {IC }}$ is evaluated by the SEPB method described in Sec. 3.4. (after Nose and Fujiii ${ }^{271}$ )

ture, ${ }^{21,23)}$ but the flat $R$-curve can be observed in the same material when the precracks are introduced into the specimens by the pop-in procedure. The difference in the $R$-curve behavior between these two types of precracks is more pronounced for a silicon-carbidewhisker-reinforced alumina. ${ }^{28)}$ A flat $R$-curve is also expected for the fatigue crack extension in coarsegrained alumina, if the crack surface is characterized by the very flat transgranular fracture appearance due to stress corrosion cracking. 27$)$ The $R$-curve seems to be flattened for the pop-in crack extension in zirconia too, ${ }^{5}$ ) although it is not yet clear whether the pop-in crack in zirconia is fully immune from the "transformation zone wake" or not.

\subsubsection{Loading Rate Dependence}

It is natural to expect that the $K_{\mathrm{IC}}$ values for brittle materials would depend little on loading rate in the range of slow loading, because ideal brittle fracture is not preceded by any time-dependent process, such as plastic deformation. It has been reported, however, that the " $K_{\mathrm{IC}}$ " value for zirconia depends on loading rate when tested in air, but it is independent of loading rate in argon atmosphere. ${ }^{29)}$ The lower $K_{\text {IC }}$ value observed at low loading rates in air can be attributed to subcritical crack growth due to stress corrosion cracking by water vapor, and the loading rate dependence is not considered to be intrinsic. These results call our attention to the test conditions, and indicate that low loading rates in normal air atmospheres should be avoided in the test to evaluate $K_{\mathrm{IC}}$.

Significant plastic deformation can occur even in ceramic materials at elevated temperatures, and the " $K_{\mathrm{IC}}$ " values come to depend on loading rate, as shown in Figs. 8(a) and 8(b). ${ }^{27,30)}$ The dependence differs with materials, which is caused by differences in the deformation mechanism and/or the manner of crack extension: e.g., the crack tip blunting by grain boundary sliding, viscous flow ahead of the crack tip, and/or extensive stable crack extension before final fracture. In addition to these phenomena, oxidation
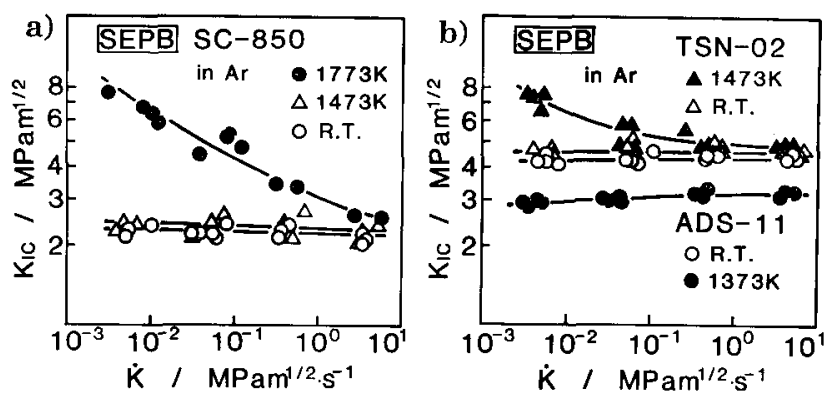

Fig. 8. Loading rate dependence of the $K_{\text {IC }}$ value: (a) for silicon carbide (SG-850), and (b) for silicon nitride (TSN-02) and alumina (ADS-11).

The $K_{\text {IU }}$ is evaluated by the SEPB method described in Sec. 3.4. (after Nose and Fujiii ${ }^{27)}$ )

and stress corrosion cracking complicate the test results in air atmospheres. The significance of the $K_{\mathrm{IC}}$ value at elevated temperatures should be fully discussed from the engineering view point, before the test conditions are decided.

\subsection{Meaning of $K_{\mathrm{IC}}$ Values Measured}

The actual fracture occurs in the presence of micrometric flaws or defects which are not so much larger than the grain size of high performance ceramics. The number of grains at the edge of each flaw or defect is several tens, which is quite small compared with that in the case of brittle fracture in metals. It is doubtful to consider the region around these flaws or defects a homogeneous body which is the premise for application of LEFM. Therefore, LEFM can only tell the average fracture process of ceramics and the occurrence of unstable fracturc is very sensitive to the heterogencity around these flaws or defects. ${ }^{31}$ The heterogeneity comprises the arrangement of grain boundaries relative to the edge of the flaw or defect, the misorientation of crystal axis at the grain boundaries, and so on, which cause the variation of local stress peaks and the inconstant occurrence of unstable crack extension. Thus, the inconstancy is inherent to the polycrystalline substance and quite different from that due to the crack size distribution in the material.

It has been reported that the " $K_{\text {IC }}$ " value decreases and the scatter increases significantly if the ratio of crack length to grain size approaches unity. ${ }^{32,33)}$ Although there remain some questions on the generality and/or the reliability of these results, ${ }^{* 2}$ the tendency might be explained in terms of the probability that the cleavage planes of grains and/or some weak grain boundaries can lie closely parallel to one another in majority of the crack front. However, such small cracks are not expected to become detectable by some non-destructive testing in the near future, and the " $K_{\mathrm{IC}}$ " value will never be directly incorporated into the design-performance criteria of structural components.

These flaws or defects are generally much smaller

*2 Such short crack length could not be adequately measured in fine-grained materials, and there is no assurance that the tendency in coarse-grained materials could be generally observed regardless of the grain size. 
than the precracks or notches which are introduced into specimens to evaluate $K_{\text {IC }}$, and the $K_{\text {IC }}$ values do not necessarily express the critical condition around these small flaws or defects. Nevertheless, the $K_{\text {IO }}$ value is a useful parameter to be referred to for improving the strength of ceramics and/or for choosing suitable materials for specific uses.

\subsection{Fracture Toughness Other than $\boldsymbol{K}_{\mathrm{IC}}$}

Dynamic fracture toughness, $K_{\text {Id }}$, is also an important parameter for components which should be used under impact loading conditions, but less research $^{29,34-36)}$ has been reported on its evaluation because of the complicated analyses needed and perhaps because of the expectation that the fracture toughness of brittle materials might be less sensitive to loading rate.

Work of fracture, $\gamma_{F}$, is another important parameter for components to be used in some setups where internal stress is dominant and decreases with crack extension, and much work has been reported concerning $\gamma_{\mathrm{F} .}{ }^{37-40)}$ However, $\gamma_{\mathrm{F}}$ is irrelevant to the fracture under more severe conditions, where stress is applied mainly from external environment, because most of the elastic energy to be dissipated with crack extension is compensated with the energy supplied from the outside. It should be noted that the first law of thermodynamics does not hold in an open system, and $\gamma_{F}$ can not always be related to the critical stress for the crack extension. "Fracture surface energy" can not be defined a priori from the physical viewpoint, but is formally converted from $K_{\mathrm{IC}}$ and Young's modulus to simulate the surface energy, $\gamma_{\mathrm{s}}$, which is clearly defined as the work done to break atomic bond.

These two parameters, $K_{\mathrm{Id}}$ and $\gamma_{F}$, are outside the scope of the present paper owing to limited space for the publication.

\section{Test Methods to Evaluate $K_{\mathrm{IC}}$}

\subsection{Precracking Techniques Conventionally Used}

Plane strain fracture toughness, $K_{\mathrm{IC}}$, is defined as " the resistance of a materials to fracture in the presence of a sharp crack", and precracks are introduced into metallic specimens by means of fatigue crack extension. ${ }^{41}$ However, such fatigue crack extension is rarely observed in ceramic materials, and some substitutive techniques are needed to introduce precracks into ceramic specimens. It has been well established that slow crack growth occurs due to stress corrosion by water vapor in air in most of ceramics. ${ }^{42,43) * 3}$ Although this crack growth can be utilized to introduce precracks into ceramic specimens, it requires too long a time to extend the crack to the requisite distance for a precrack. More rapid crack growth might occur in more corrosive environments, ${ }^{43)}$ but it would spoil the virgin state of the grain boundaries ahead of the crack tip. Wedge loading at a saw notch is an alternative technique, ${ }^{44)}$ but it can only be applied to rather large specimens such as the edgecracked tension specimen, the "compact tension" specimen (CT), and the "double cantilever beam" specimen (DCB). Furthermore, the stable crack extension induced by wedge loading might be accompanied by an increase in crack resistance as described in Sec. 2.2. Thermal shock can induce some crack extension from the notch in a bend specimen, ${ }^{45}$ but the crack extension would not be uniform and the crack path would easily be deflected, reflecting the asymmetry of heating and cooling. Therefore, essentially, the most important point is how to introduce a precrack into a specimen for $K_{\mathrm{IC}}$ measurement of ceramics. In other words, various $K_{\text {IC }}$ test methods have been proposed to improve the quality of the precrack, as described below.

\subsection{Single-edge-notched-beam Method}

In the "single-edge-notched-beam" method (SENB), ${ }^{46,47)}$ a narrow-gapped notch (i.e., a saw cut notch) takes the place of the precrack in a bend specimen, as shown in Fig. 9(a), in expectation that a crack straight through the thickness of the specimen might develop at the notch root during a three-point bend test to obtain $K_{\mathrm{IO}}$. $\quad\left(K_{\mathrm{IC}}\right.$ is calculated from Srawley's formula. ${ }^{41,48)}$ ) The expectation, however, could only be met by the use of a very thin diamond wheel cutter of high price, which would never come into common use. By the use of the cutter of a conventional width, e.g., more than $0.1 \mathrm{~mm}$, the " $K_{\mathrm{IC}}$ " value of ceramic materials differs with laboratory, reflecting the difference in the notch root radius and/ or the cutting procedures: e.g., the average values for silicon nitride were $6.0 \mathrm{MPa} \mathrm{m}^{1 / 2}$ in one laboratory and $7.3 \mathrm{MPa} \mathrm{m} \mathrm{m}^{1 / 2}$ in another laboratory by five tests for each. ${ }^{2)}$

\subsection{Cheoron-notched-beam Method}

The trouble in the SENB method has been expected to be circumvented by the "chevron-notchedbeam " method (CNB), ${ }^{49,50)}$ where stable crack extension is assumed to occur from the apex of a chevron-shaped ligament shown in Fig. 9(b) during a four-point bend test to obtain $K_{1 \mathrm{c}}$. The stress intensity factor, $K_{\mathrm{I}}$, around the crack tip has been discussed by various workers, although almost all the results reported are not based on any three dimensional analysis but have been derived by accommo-

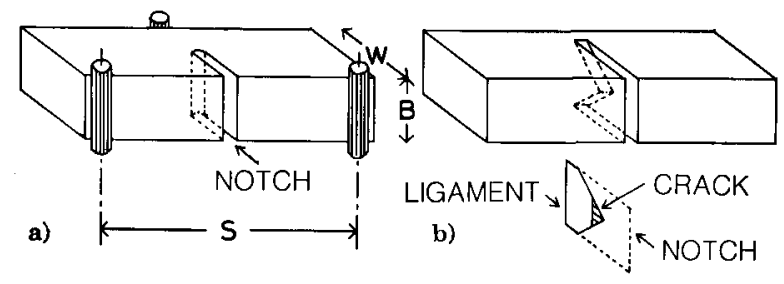

Fig. 9. (a) A notch straight through the thickness of the single-edge-notched-beam (SENB), and (b) a crack extended from the apex of a chevron-shaped ligament in the chevron-notched-beam (CNB). 
dating the joints of two dimensional analyses: e.g., Bluhm's slice model. ${ }^{51)}$ Among these, Munz's formula has been widcly used to calculate the $K_{\mathrm{IC}}$ value, because the $K_{\mathrm{I}}$ is expressed in an analytical form. ${ }^{50}$ ) (It should be cautioned not to mistake the formula as an analytical solution. Munz's formula, as well as Srawley's formula, is an approximate one which was fitted to the results of numerical analyses in a limited range of the notch depth and shape.) Even by the CNB method, the " $K_{\text {IC }}$ " value of a ceramic material differed with laboratory, ${ }^{2-4)}$ as shown in Fig. 10, perhaps mainly because the stable crack extension does not necessarily precede the occurrence of unstable fracture of the specimen.*4 Furthermore, the stable crack extension by the CNB method is destined to be accompanied by the crack resistance increase in some ceramic materials, ${ }^{52)}$ as described in Sec. 2.2. Incidentally, similar problems are expected to arise in the short rod or short bar specimens with chevron notches under flatjack loading. ${ }^{53)}$

\subsection{Single-edge-precracked-beam Method}

To introduce a precrack into a hard metal specimen, Sadahiro ${ }^{54)}$ applicd a simple and ingenious technique, which had originally been devised by Nunomura and Jitsukawa to promote the extension of median/radial cracks from the Vickers indentations in bearing steels. ${ }^{55}$ ) The precracking tcchnique was termed the "bridge-indentation " method (BI), ${ }^{56)}$ and has been improved by the present authors for its application to introduction of precracks into small ceramic specimens. ${ }^{27,30,57,58) * 5}$ As shown in the middle portion of Fig. 11, a crack extends upwards from a crack starter such as a Vickers impression in a beamshaped specimen, when the specimen is compressed with a centrally-grooved anvil and a flat-bottomed pusher. Eventually the crack front is arrested as a straight line through the thickness of the specimen. Thus, desirable precracks can be conveniently introduced, and the trouble resulting from the SENB method is removed. The specimen is schematically shown in Fig. 12(a). The crack can be further extended stably by increasing the compressive load. The cracking process was clarified by the finite element method analysis on the variation of the stress intensity factor with virtual crack extension. (See Ref. 27) for details.) The " $K_{\text {IC }}$ " value for some materials differs with the way of crack extension, popin or stable extension, as already shown in Fig. 7 and described in Sec. 2.2. ${ }^{* 6}$

The precracked specimen is subjected to a threepoint bend test, and $K_{10}$ is calculated either from

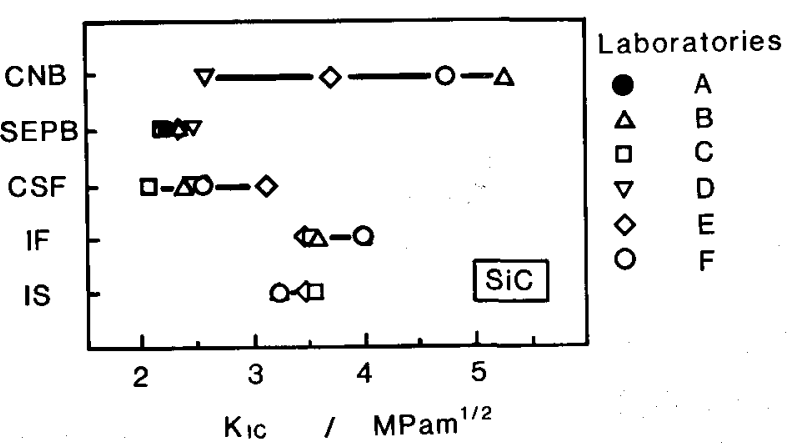

Fig. 10. Examples of round robin test results by the J.F.C.A. Research Committee, picked up from Ref. 4).

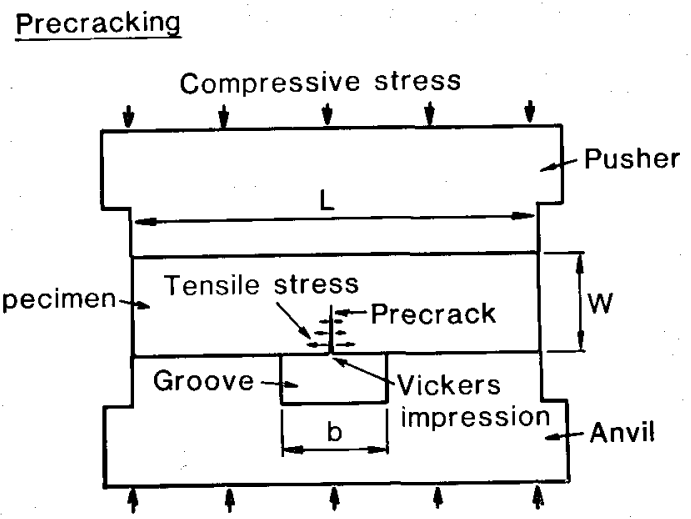

Fig. 11. Schematic of the bridge-indentation method. (after Nose and Fujiii ${ }^{27)}$ )

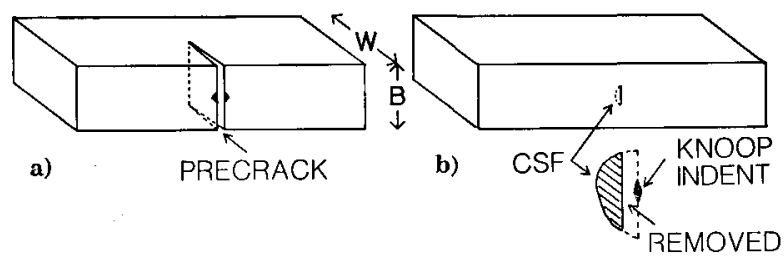

Fig. 12. (a) A precrack straight through the thickness of the single-edge-precracked-beam (SEPB), and (b) a semicircular precrack used in the controlled-surface-flaw method (CSF).

Srawley's formula, ${ }^{41,48)}$ or from Wakai et al.'s formula ${ }^{59)}$ in case that the support span is not equal to four times the specimen width. The method is temporarily termed the "single-edge-precracked-beam" method (SEPB), on the analogy of the SENB method. The agreement between the $K_{\mathrm{IC}}$ values by different laboratories is good, as shown in Fig. 10. The SEPB method was adopted in the original form of a JIS because of the theoretical validity and the experimental

*4 It is strange to say that notches have been simply considered to be geometrical singular portions without being accompanied by any microstructural change which could affect the stress state around the notch root, in a striking contrast to the case of cracks on which even a small microscopic change has been considered to affect the fracture resistance.

* 5 Most of structural components of ceramic materials are too small to provide larger specimens. Larger specimens of the same compositions do not necessarily have the same properties as those of small components, because their properties are also affected by the manufacturing processes.

* Some papers other than ours have also reported the evaluation of $K_{\mathrm{IC}}$ using specimens precracked by the BI method, but all of them do not explicitly describe the procedure by which the precracks were introduced: pop-in or stable crack extension. ${ }^{54,56)}$ Similar cracks can be stably extended by displacement-controlled loading with an extremely stiff device. ${ }^{22}$ ) 
reproducibility. Incidentally, the SEPB method can give $K_{\mathrm{s}}$ values identical to those by the single-edgefatigue-cracked-beam method (SECB) for coarsegrained alumina. ${ }^{27)}$ Flat $R$-curve in coarse-grained alumina can only be observed by the SEPB method (pop-in precracked), or by the SECB method.

\subsection{Controlled-surface-flaw Method}

The median/radial crack, which will be described in the next paragraph, can be utilized as a precrack in a beam-shaped specimen, as shown in Fig. 12(b). In the "controlled-surface-flaw" method (CSF), ${ }^{60)}$ the residual stress due to the indentation must be eliminated either by polishing or by annealing the specimen, and much skill is required to distinguish the semicircular crack front, which appears to be a barrier to the common use of this technique. The flawed specimen is subjected to a bend test (threepoint or four-point) to obtain $K_{\mathrm{IC}}$. The stress intensity factor, $K_{1}$, around the semicircular crack front was derived both by Shah-Kobayashi ${ }^{611}$ and by RajuNewman. ${ }^{62)}$ The agreement between the $K_{\mathrm{IC}}$ values by different laboratories is fair, as shown in Fig. 10.

\subsection{Indentation-fracture Method}

The above-mentioned methods are well theoretically based on LEFM, although care should be taken that the real specimens are prepared to fit the premises of LEFM. On the other hand, some simpler methods have been proposed to evaluate $K_{\mathrm{IC}}$, based on simplified models of crack formation from a Vickers indentation in a ceramic specimen. Plastic deformation can not fully diffuse out the volume reduction impressed by the Vickers indentation in ceramic materials, and several types of cracks are known to form in the surrounding region. Among these, the median/radial crack length, " $2 c$ " in Fig. 13, has been thought to be related to the $K_{1 \mathrm{C}}$ value of the material, and various models have been proposed in the " indentation fracture " method (IF). ${ }^{63-69)}$ The IF method is very convenient because it suffices to measure the diagonal of the indentation, $2 a$, and the crack length, $2 c$. The " $K_{\text {IC }}$ " value can easily be calcu-

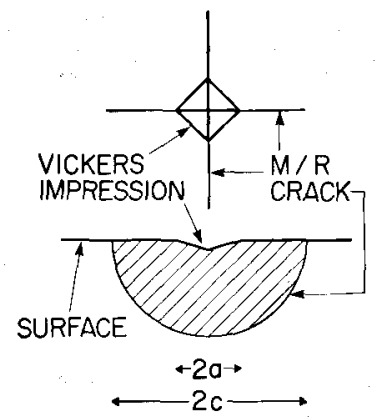

Fig. 13. Schematic of median/radial (M/R) crack around the Vickers impression. lated from the indentation load, the diagonal of the indentation, the crack length, and Young's modulus. ${ }^{* 7}$ It is troublesome, however, that the " $\boldsymbol{K}_{\mathrm{IC}}$ " value differs with the proposed formula, due to the differences in the models, in the reference materials, and in the reference test method ${ }^{* 8}$ by which the $K_{I C}$ values were measured to fit those parameters mentioned above.

As shown in Fig. 10, the difference in the " $K_{\mathrm{IC}}$ " values between laboratories is small compared with its difference between the formulae, and these values were well correlated with $K_{\mathrm{IC}}$ values by the SEPB method for alumina, silicon carbide, and silicon nitride in the round robin tests carried out by the J.F.C.A. research committee. ${ }^{2-5)}$ (The " $K_{1 C}$ " values by the IF method in Fig. 10 were calculated from Niihara et al.'s formula. ${ }^{67)}$ ) The coincidence and the good correlation put forward the re-examination of the empirical expression to calculate the " $K_{\mathrm{IC}}$ " value, because the handiness is the advantage of the IF method in limited uses such as the quality control of known materials. As the consequence, the IF method was also included in the original form of a JIS, where the " $K_{1 C}$ " value has been denoted by $K_{C}$ to be distinguished from $K_{\mathrm{IC}}$ evaluated by the SEPB method. It should be noted, however, that the IF method is useless to evaluate $K_{\mathrm{C}}$ of some materials, where median/radial cracks are obscure, and there is no assurance that the method can be always applied to newly-developed materials.

\subsection{Indentation-strength Method}

The above-mentioned median/radial crack further extends under the flexural stress upon bending, and the crack extension was analyzed in a similar manner to that in the IF method. The precracked specimen is subjected to a bend test (three-point or four-point) to obtain $K_{\mathrm{IO}}$. The " $K_{\mathrm{IC}}$ " valuc can be easily calculated from Young's modulus, Vickers hardness, the indentation load, and the maximum flexural stress, at which unstable crack extension occurs. The test method has been termed the "indentation-strength" method (IS), ${ }^{70)}$ and is convenient because the crack length need not be measured. The difference in the " $K_{1 G}$ " values between laboratories was small, as shown in Fig. 10, when the indentation load is a fixed value, e.g., $198 \mathrm{~N}$. However, the " $K_{\mathrm{IC}}$ " value seems to vary with the indentation load, ${ }^{3,4)}$ perhaps owing to the simplified model for the crack formation and extension.

\subsection{The Other Methods}

The "double-torsion" method (DT) "11) and the "double-cantilever-beam" method (DCB) ${ }^{72)}$ had been early developed, but have not yet come into common use. The DT method needs large specimens which restrict its applications, ${ }^{* 5}$ although machining

\footnotetext{
*7 It is interesting to note that a technique, which originated from an effort to apply the IF method to bearing steels, ${ }^{55)}$ has developed into the beforc-mentioned BI method, a new precracking technique for ceramic materials.

*8 The formulae in the IF method were derived by fitting them with the $K_{\text {IC, values measured either by the DT method }}{ }^{64-67)}$ or the DCB method, ${ }^{68)}$ except for the one ${ }^{69)}$ which was derived by a finite element method bascd on an idealized model for the median/radial crack.
} 
of the specimen is rather simple. The crack front is curved through the thickness direction, and the $K_{\mathrm{I}}$ is not constant along the crack front, although the DT method has an advantage in that the crack length need not be measured to calculate the $K_{\text {IO }}$ value. The DCB specimen need not be so large, but restrictions arise from the high cost for machining the specimen and the sophisticated fixture for loading. It has been shown that the $K_{\mathrm{IO}}$ values of yttria-stabilizedzirconia measured by the DCB method agree well with those by the SEPB method. ${ }^{73)}$ The "compacttension" method (CT) has been in common use for metals, ${ }^{41,74)}$ but has not been used as a test method for ceramics because of the difficulty in piercing brittle materials.

\section{Summary}

The present paper has attempted primarily to introduce the test methods for $K_{\mathrm{IC}}$ values of ceramic materials, and secondly to comment on the precautions in using the test methods. The test methods should be by nature independent of the toughening mechanism of the material to be tested, but actually they are more or less burdened with nuisances incidental to the toughening mechanism because of the low $K_{\mathrm{IC}}$ values for ceramic materials. The original form of a JIS for the $K_{\text {IC }}$ test method was approved by the J.F.C.A. examination committee. Also, an international round robin test is now in progress for the standardization of test methods to evaluate $K_{\mathrm{lc}}$. Time is ripe now and the standardization is expected to accelerate the understanding of material properties, the material development, and the practical use of ceramic materials.

\section{REFERENCES}

1) R.W. Rice: Fracture Mechanics of Ceramics, Vol. 1, Plenum Press, New York, (1974), 323.

2) Research Report on the Standardization of Fine Ceramics, Japan Fine Geram. Assoc., Tokyo, (Mar. 1985), 99, (in Japanese).

3) Research Report on the Standardization of Fine Ceramics, Japan Fine Ceram. Assoc., Tokyo, (Mar. 1986), 67, (in Japanese).

4) Research Report on the Standardization of Fine Ceramics, Japan Fine Ceram. Assoc., Tokyo, (Mar. 1987), 41, (in Japanese).

5) Research Report on the Standardization of Fine Ceramics, Japan Fine Ceram. Assoc., Tokyo, (Mar. 1988), 96, (in Japanese).

6) D. J. Green: Fracture Mechanics of Ceramics, Vol. 5, Plenum Press, New York, (1983), 457.

7) Y. M. Ito: Fracture Mechanics of Ceramics, Vol. 5, Plenum Press, New York, (1983), 479.

8) R. G. Hoagland and J. D. Embury: J. Am. Ceram. Soc., $63(1980), 404$

9) A. G. Evans and K. T. Faber: J. Am. Ceram. Soc., 64 (1981), 394.

10) M. Kachanov and E. Montagut: "Interaction of a Crack with Certain Microcrack Arrays", Eng. Fracture Mech., 25 (1986), Nos. 5/6, 625, (C) 1986. Reprinted with permission of Pergamon Press PLC.

11) S.W. Freiman: "Brittle Fracture Behavior Ceramics",
Am. Ceram. Soc. Bull., 67 (Feb., 1988), No. 2, 392, (C) 1988. Reprinted by permission of the American Ceramic Society.

12) K. T. Faber and A. G. Evans: Acta metall., 31 (1983), 577.

13) P. L. Swanson, C. J. Fairbanks, B. R. Lawn, Y.-W. Mai and B. J. Hockey: J. Am. Ceram. Soc., 70 (1987), 279.

14) F. F. Lange: Phil. Mag., 22 (1970), 983.

15) R. F. Becher and V.J. Tennery: Fracture Mechanics of Ceramics, Vol. 6, Plenum Press, New York, (1983), 383.

16) S. W. Freiman, L. Chuck, J. J. Mecholsky, Jr., D. L. Shellman and L. Storz: Fracture Mechanics of Ceramics, Vol. 8, Plenum Press, New York, (1986), 175.

17) A. G. Evans and A. H. Heuer: J. Am. Ceram. Soc., 63 (1980), 241.

18) D. B. Marshall and J. D. Ritter: Am. Ceram. Soc. Bull., 66 (1987), 309.

19) M. V. Swain: Acta metall., 33 (1985), 2083.

20) D. B. Marshall, A. G. Evans and M. Drory: Fracture Mechanics of Ceramics, Vol. 6, Plenum Press, New York, (1983), 289.

21) D. B. Marshall: J. Am. Ceram. Soc., 69 (1986), 173.

22) H. Wieninger, K. Kromp and R. F. Pabst: J. Mater. Sci., 21 (1986), 411, (C) 1986. Reprinted by permission of Chapman and Hall.

23) R. Knehans and R. Steinbrech: J. Mater. Sci. Lett., 1 (1982), 327.

24) F. Deuerler, R. Knehans and R. Steinbrech: J. Phys., 47 (1986), C1-617.

25) A. G. Evans and T. G. Langdon: Progress in Materials Science, Vol. 21, Plenum Press, New York, (1976), 275.

26) T. Nose, T. Fujii and I. Soya: Telsu-to-Hagané, 73 (1987), S729.

27) T. Nose and T. Fujii: “ Evaluation of Fracture Toughness for Ceramic Materials by a Single-Edge-Precracked-Beam Method ", J. Am. Ceram. Soc., 71 (May, 1988), No. 5, 328, (C) 1988. Reprinted by permission of the American Ceramic Society.

28) T. Nose, T. Fujii and H. Kubo: Collected Abstracts of 1988 Autumn Meeting of Japan Inst. Metals, (1988), 205, (in Japanese).

29) K. Suzuki, T. Kishi, T. Kihara and S. Kohara: Tetsu-toHagané, 73 (1987), S1454; Preprints, 949th Meeting Japan Soc. Mech. Eng., (1987), 84, (in Japanese).

30) T. Nose and T. Fujii: Preprints, S62 Annual Meeting of Japan Ceram. Soc., Tokyo, (May 1987), (in Japanese).

31) M.J. Noone and R. L. Mehan: Fracture Mechanics of Ceramics, Vol. 1, Plenum Press, New York, (1974), 201.

32) R. W. Rice, S. W. Freiman and J.J. Mecholsky, Jr.: J. Am. Ceram. Soc., 63 (1980), 129.

33) R. F. Cook, B. R. Lawn and C. J. Fairbanks: J. Am. Ceram. Soc., 68 (1985), 604; Fracture Mechanics of Ceramics, Vol. 8, Plenum Press, Ncw York, (1986), 23.

34) B. Tolba, P. Becker and G. Pluvinage: Colloq. Metall., 27 (1984), 169, (in French).

35) T. Kobayashi, K. Matsunuma, H. Ikawa and K. Motoyoshi: J.Jpn. Inst. Met., 51 (1987), 723.

36) M. Sakata, S. Aoki, K. Kishimoto, Y. Fujino and T. Akiba: Preprints, 949th Meeting Japan Soc. Mech. Eng., (1987), 86, (in Japanese).

37) G. D. Swanson: J. Am. Ceram. Soc., 55 (1972), 48.

38) A. G. Evans: Fracture Mechanics of Ceramics, Vol. 1, Plenum Press, New York, (1974), 17.

39) M. Sakai, R. C. Bradt and A. S. Kobayashi: J. Ceram. Soc. $J p n ., 96$ (1988), 525, (in English).

40) K. Hayashi, Y. Tatewaki, S. Ozaki and T. Nishikawa: $J$. Ceram. Soc. Jpn., 96 (1988), 532, (in Japanese).

41) E399-83, Annual Book of ASTM Standard, Vol. 03.01, (1987), 680.

42) S. M. Wiederhorn: J. Am. Ceram. Soc., 50 (1967), 407. 
43) S. M. Wiederhorn, S. W. Freiman, E. R. Fuller, Jr. and C. J. Simmons: J. Mater. Sci., 17 (1982), 3460.

44) R. G. Hoaguland, A. R. Rosenfield and G. T. Hahn: Metall. Trans., 3 (1972), 123.

45) R. Betolotti: J. Am. Ceram. Soc., 56 (1973), 107.

46) R. F. Pabst: Fracture Mechanics of Ceramics, Vol. 2, Plenum Press, New York, (1974), 555.

47) J. L. Henshall, D. J. Rowcliffe and J. W. Edington: J. Mater. Sci., 9 (1974), 1559.

48) J. E. Srawley: Int. J. Fracture, 12 (1976), 475.

49) D. Munz, R. T. Bubsey and J. L. Shannon, Jr.: J. Am. Ceram. Soc., $63(1980), 300$.

50) D. Munz, J. L. Shannon, Jr. and R. T. Bubsey: Int. J. Fracture, 16 (1980), R137.

51) J. T. Bluhm: Eng. Fracture Mechanics, 7 (1975), 593.

52) H. Kobayashi, H. Nakamura, A. Kitayama and B. Ote: J. Soc. Mater. Sci. Jpn., 35 (1986), 892, (in Japanese).

53) L. M. Baker: ASTM Spec. Tech. Publ, 678, (1979), 73.

54) T. Sadahiro and S. Takatsu: Modern Developments in Powder Metallurgy, Vol. 24, Metal Powder Indust. Feder., Princeton, (1981), 561; J.Jpn. Inst. Met., 45 (1981), 291.

55) S. Nunomura and S. Jitsukawa: Tetsu-to-Hagané, 64 (1978), $\mathrm{S} 853$.

56) R. Warren and B. Johanneson: Powder Metall., 27 (1984), 25.

57) T. Nose and T. Fujii: Preprints, S61 Annual Meeting of Japan Geram. Soc., Tokyo, (May 1986), (in Japanese).

58) T. Nose and T. Fujii: Tetsu-to-Hagané, 72 (1986), S1570.

59) F. Wakai, S. Sakaguchi and Y. Matsuno: J. Ceram. Soc. Jpn., 93 (1985), 479, (in Japanese).
60) J. J. Petrovic and M. G. Mendiratta: ASTM Spec. Tech. Pub. 678, (1979), 83.

61) R. C. Shah and A. S. Kobayashi: ASTM Spec. Tech. Pub. 513, (1972), 3 .

62) I. S. Raju and J. C. Newman, Jr.: Report No. TMX72825, Nat. Aeronau. Space Administr., TX, (1977).

63) B. R. Lawn and E. R. Fuller: J. Mater. Sci., 10 (1975), 2016.

64) D. B. Marshall and B. R. Lawn: J. Mater. Sci., 14 (1979), 2001.

65) B. R. Lawn, A. G. Evans and D. B. Marshall: J. Am. Ceram. Soc., $63(1980), 574$.

66) D. B. Marshall and A. G. Evans: J.Am. Ceram. Soc., 64 (1981), C-182.

67) K. Niihara, R. Morena and D. P. Hasselman: J. Am. Ceram. Soc., 65 (1982), C-116.

68) G. R. Anstis, P. Chantikul, B. R. Lawn and D. B. Marshall: J. Am. Ceram, Soc., 64 (1981), 533.

69) T. Miyoshi, N. Sagawa and T. Sassa: Trans. Jpn. Soc. Mech. Eng., 51A (1985), 2489, (in Japanese).

70) P. Chantikul, G. R. Anstis, B. R. Lawn and D. B. Marshall: J. Am. Ceram. Soc., 64 (1981), 539.

71) A. G. Evans: J. Mater. Sci, 7 (1972), 1137.

72) S. M. Wiederhorn, A. M. Shorb and R. L. Moses: J. Appl. Phys., 39 (1968), 1569.

73) T. R. Lai, C. L. Hogg and M. V. Swain: ISIJ Int., 29 (1989), 240.

74) W. F. Brown and J. E. Srawley: ASTM Spec. Tech. Pub. 410, (1966), 12. 